\title{
Regulation of Nod1-mediated signaling pathways
}

\author{
J da Silva Correia ${ }^{1}$, Y Miranda ${ }^{1}$, N Leonard ${ }^{1}$, J Hsu ${ }^{1}$ and RJ Ulevitch ${ }^{\star, 1}$
}

Nod1 is a member of the NLR/Nod/CATERPILLER family. It acts as a sensor for intracellular bacteria by recognizing specific glycopeptides derived from peptidoglycan. Nod1 activation mediates distinct cellular responses including activation of MAP kinases, IL-8 release, apoptosis and suppression of several estrogen-dependent responses in MCF-7 cells. Here we have extended these studies by identifying key regulatory steps in Nod1-dependent signaling pathways. We provide multiple lines of data showing that Nod1-dependent apoptosis is a caspase 8-mediated event and that apoptosis requires RIP2. In contrast, several lines of evidence show that Nod1-dependent JNK activation and IL-8 production did not require the presence of caspase 8 but required activation of TAK1 as well as RIP2. Thus, we have identified several key control points that lie downstream of Nod1. This work provides the basis for further studies of the biological significance and regulation of the Nod1 pathway. Cell Death and Differentiation (2007) 14, 830-839. doi:10.1038/sj.cdd.4402070; published online 22 December 2006

Nod1 is a cytosolic protein and a member of a family of proteins known as the NLR/Nod/CATERPILLER family. ${ }^{1,2}$ This protein family also includes a closely related protein known as Nod2. ${ }^{3}$ Nod1 and Nod2 are thought to function in innate and adaptive immunity, inflammation as well as a variety of other processes that determine the balance between health and disease. The most clearly defined function for these proteins is in recognition of intracellular bacteria primarily through sensing glycopeptides derived from microbial peptidoglycan. ${ }^{4-6}$ NLR family members are characterized by a centrally located oligomerization and nucleotide-binding domain (NBD) domain that is followed by multiple leucine-rich repeat domains at the carboxy-terminus. The effector functions of NLR family members are determined by the sequence of the amino terminal domains; Nod1 contains a single caspase recruitment domain (CARD) domain whereas Nod2 contains two CARD domains that provide binding sites for other CARD domain containing proteins. Current models that explain how Nod1 and Nod2 undergo ligand-dependent activation suggest that there is a ligand-dependent selfassociation step that facilitates binding of additional proteins which determine various downstream signaling events. ${ }^{7}$ Activation of Nod1 and Nod2 initiate a variety of cellular responses including NF- $\kappa \mathrm{B}$ and MAPK activation, cytokine production and apoptosis. $^{8-10}$

Recently we described an unanticipated Nod1-dependent pathway of apoptosis and control of the growth of the estrogen-sensitive breast cancer cell line, MCF-7 cells. ${ }^{9} \mathrm{We}$ reported how addition of the Nod1 peptidic ligand, Ala- $\gamma$ Gludiaminopimelic acid ( $\gamma$ TriDAP), induced apoptosis and IL-8 secretion in MCF-7 cells. These responses require Nod1 protein expression. This was clearly shown because we isolated and characterized a Nod1-deficient cell clone we termed MCF-7 C20 that failed to respond to $\gamma$ TriDAP until we re-expressed Nod1 wt protein. ${ }^{9}$ The Nod1-expressing C20 clone regained sensitivity to $\gamma$ TriDAP as measured by either IL-8 secretion or induction of cell death. Here we have utilized MCF-7 cells to further define the downstream signaling pathways that initiate multiple cellular responses that depend on activation of Nod1 by its specific ligand. These responses include Nod1-dependent apoptosis, JNK activation and IL-8 production. We show that RIP2 is a key component of Nod1 signaling controlling both JNK and apoptosis. Most surprisingly expression of a kinase-dead form of RIP2 supports Nod1-dependent events as well as a kinase-active (wt) form of RIP2. Further we showed that the kinase TAK1 is important for JNK activation but not for Nod1-dependent apoptosis. In fact we noted that expression of a kinase-dead form of TAK1 markedly increased the sensitivity of MCF-7 cells to cell death. Finally, we showed that in MCF-7 cells Nod1-dependent apoptosis is dependent on caspase 8 . In totality these data provide a new understanding of the molecular mechanisms of Nod1 signaling pathways.

\section{Results}

The P-loop residue K208 is required for ligand-dependent Nod1 signaling in activation of MCF-7 cells. We first wished to extend previous findings suggesting that the K208 residue within the P-loop of Nod1 is important for functional responses. ${ }^{11}$ However, the previous study used transient overexpression of Nod1 in 293 cells where activation of Nod1 resulted from overexpression rather than from a liganddependent event. It is important to note that all experiments described here use the Nod1-specific ligand $\gamma$ TriDAP to study activation of Nod1 in MCF-7 cells. Thus, we used the Nod1deficient MCF-7 C20 line to establish a stably transfected clone expressing the K208R mutant. Cells were stimulated with $\gamma$ TriDAP in the presence of cycloheximide $(\mathrm{CHX})$ to

\footnotetext{
${ }^{1}$ Department of Immunology, The Scripps Research Institute, La Jolla, CA, USA

*Corresponding author: RJ Ulevitch, Department of Immunology, The Scripps Research Institute, 10550 North Torrey Pines Road, La Jolla, CA 92037, USA.

Tel: 858784 8219; Fax: 858-784-8239; E-mail: ulevitch@scripps.edu

Keywords: Nod1; RIP2; signal transduction; caspase 8; MCF-7 cells

Abbreviations: CARD, caspase recruitment domain; CHX, cycloheximide; $\gamma$ TriDAP, Ala- $\gamma$ Glu-diaminopimelic acid

Received 06.4.06; revised 11.10.06; accepted 25.10.06; Edited by H Ichijo; published online 22.12.06
} 
enhance the responses of MCF-7 cells. Expression of Nod1 with the K208R mutation completely prevented Nod1dependent JNK activation, apoptosis and IL-8 secretion (Figure 1a-c). Expression levels for Nod1 wt and Nod1 K208R protein was similar as shown by Western blot analysis (Figure 1d). Thus, the K208 residue in the P-loop is important in ligand-dependent activation of Nod1 for each of the three pathways investigated.

RIP2 is a critical component of Nod1 signaling pathways in MCF-7 cells. Nod1 activation is thought to involve formation of a multiprotein signaling complex that includes
RIP2. ${ }^{7}$ A role for RIP2 was first identified by others using transient expression in 293 cells and in studies with RIP2 knockout mice. ${ }^{12,13}$ Here we further analyzed the role of RIP2 by specifically evaluating the role of two of its principal domains: the CARD and the kinase domains. Stable expression of RIP2 lacking its CARD domain in MCF-7 cells completely abrogated Nod1-induced JNK activation, cell death and IL-8 secretion (Figure $2 a, c$ and d). Thus, this truncated form of RIP2 acts as a dominant-negative protein. In contrast, stable overexpression of RIP2 wt or a catalytically inactive RIP2 (RIP2-KD) substantially increased each of the pathways measured when compared to

a
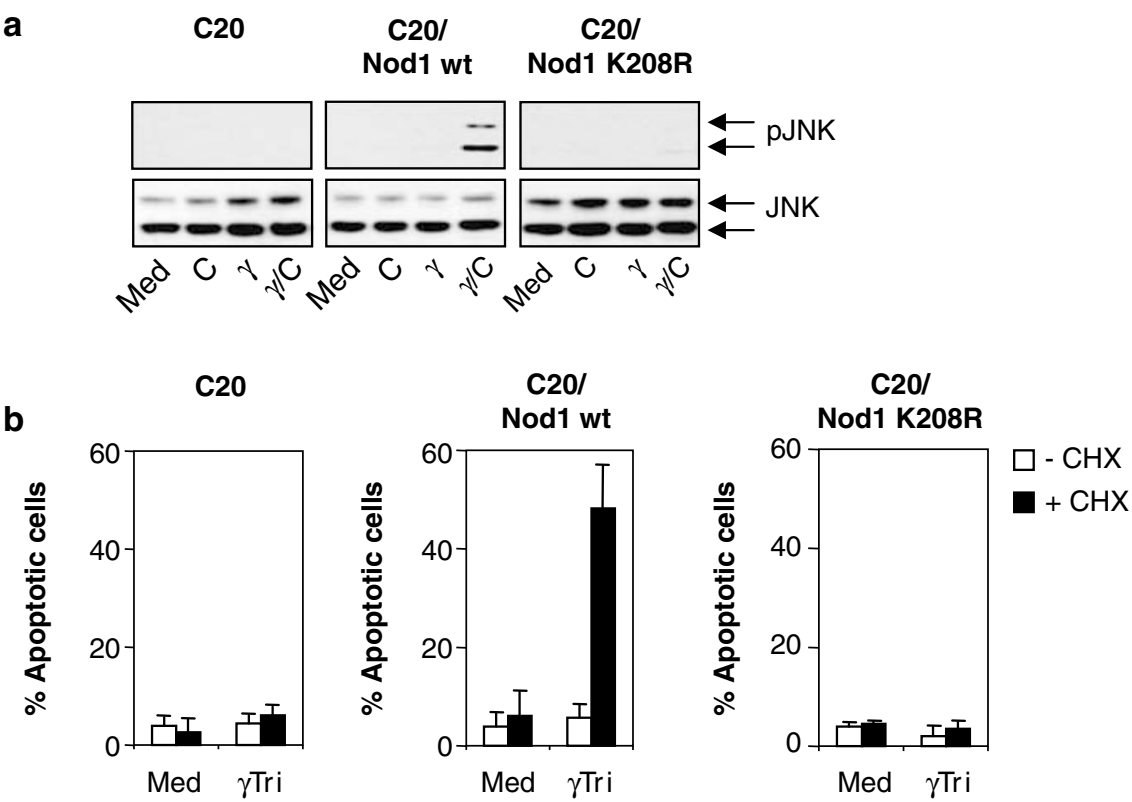

C
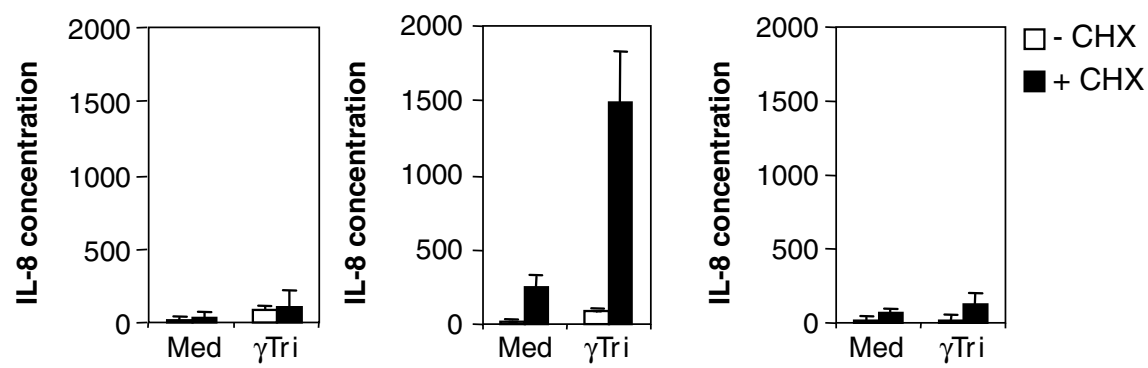

d

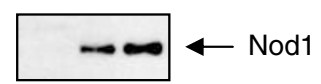

123

Figure 1 The P-loop residue K208 of Nod1 is important for $\gamma$ TriDAP-induced JNK activation, apoptosis induction and IL-8 release in MCF-7 cells. (a) MCF-7 C20, MCF-7 C20 stably expressing either Nod1 wt (MCF-7 C20/Nod1) or Nod1 K208R (MCF-7 C20/Nod1 K208R) were left untreated or treated with $\gamma$ TriDAP (20 $\mu \mathrm{g} / \mathrm{ml})$ in the presence or absence of $\mathrm{CHX}(0.5 \mu \mathrm{g} / \mathrm{ml})$ for $2 \mathrm{~h}$. Cell lysates were prepared and phosphorylation of JNK was analyzed using anti-phospho JNK (Thr183/Tyr185) antibody. The same blots were reprobed for anti-JNK expression, indicating equal protein loading under all conditions. (b) Cells were left untreated or treated with $\gamma$ TriDAP in the presence or absence of $\mathrm{CHX}(3 \mu \mathrm{g} / \mathrm{ml})$ for $48 \mathrm{~h}$. Cells were incubated with PI and apoptotic cell death was measured by flow cytometry. (c) Cells were stimulated with $\gamma$ TriDAP in the presence or absence of $\mathrm{CHX}(0.5 \mu \mathrm{g} / \mathrm{ml})$ for $24 \mathrm{~h}$. Cell supernatants were harvested and assayed for IL-8 secretion. Data are expressed as mean \pm S.D. of four independent experiments. (d) Expression of Nod1 in MCF-7 C20 (lane 1), MCF-7 C20/Nod1 wt (lane 2) and MCF-7 C20/Nod1 K208R (lane 3) was confirmed by Western blot analysis using anti-Myc antibody 
a
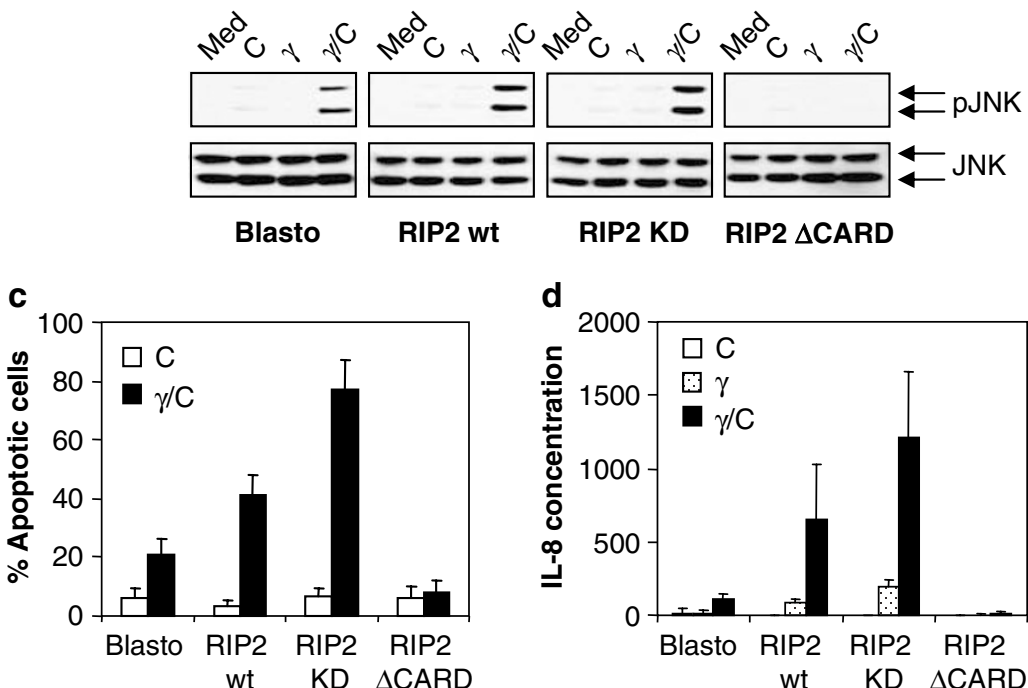

d

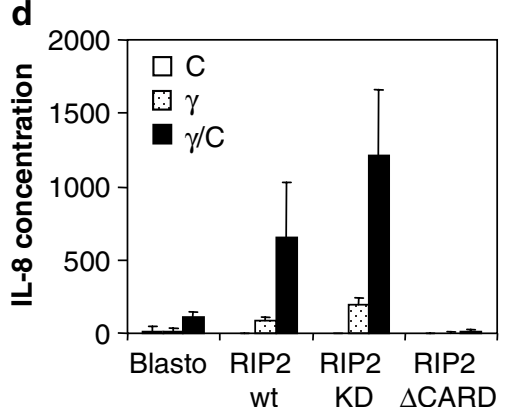

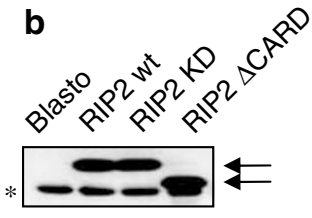

e

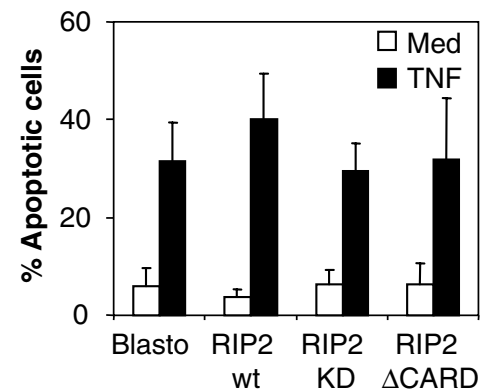

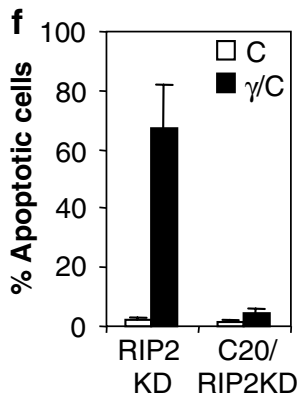
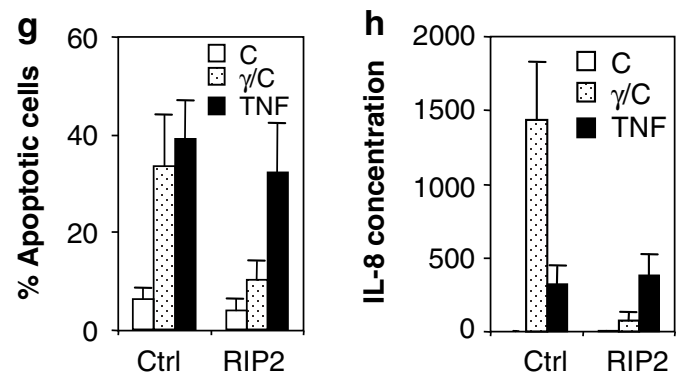

i

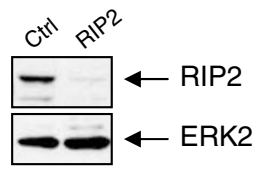

Figure 2 RIP2 is a critical component of Nod1 signaling pathways. (a) MCF-7 cells were stably transfected with empty vector (Blasto), Myc-RIP2 wt, Myc-RIP2-KD and Myc-RIP2- $\triangle$ CARD and were left untreated or treated with $\gamma \operatorname{TriDAP}(\gamma)$ in the presence or absence of $\mathrm{CHX}(\mathrm{C}, 0.5 \mu \mathrm{g} / \mathrm{ml})$ for $2 \mathrm{~h}$. Cell lysates were prepared and phosphorylation of JNK was analyzed using anti-phospho JNK antibody. (b) Expression of RIP2 proteins was confirmed by immunoprecipitation of cell extracts with polyclonal anti-Myc antibody and immunoblotting using monoclonal anti-Myc 9E10 antibody. ${ }^{*}$ Indicates an unspecific band. (c) Cells were treated with $\gamma$ TriDAP in the presence or absence of $\mathrm{CHX}(3 \mu \mathrm{g} / \mathrm{ml})$ for $48 \mathrm{~h}$. Cells were incubated with PI and apoptotic cell death was measured by flow cytometry. (d) Cell supernatants were harvested and assayed for IL-8 secretion. (e) Cells were stimulated with TNF $\alpha(10 \mathrm{ng} / \mathrm{ml})$ for $18 \mathrm{~h}$ and cell death was measured by flow cytometry. (f) MCF-7 RIP2-KD and MCF-7 C20/RIP2-KD were treated with $\gamma$ TriDAP in the presence or absence of $\mathrm{CHX}(3 \mu \mathrm{g} / \mathrm{ml})$ and cell death was measured by flow cytometry. ( $\mathbf{g}$ and $\mathbf{h})$ MCF-7 Nod1 cells were transfected with $5 \mathrm{nM}$ RIP2-targeting siRNA and cultured for $72 \mathrm{~h}$. Cells were stimulated with $\gamma$ TriDAP/CHX and apoptosis (g) and IL-8 release (h) determined. (i) Depletion of endogenous RIP2 protein was confirmed by Western blot using anti-RIP2 antibody. The same blot was reprobed for anti-ERK2, indicating equal protein loading

responses of the parental MCF-7 cells transfected with a control vector. Expression of each protein was nearly equivalent as shown in Western blots (Figure 2b). In contrast to effects on the Nod1 pathway, expression of the RIP2 constructs did not change TNF $\alpha$-induced cell death (Figure 2e) or IL-8 production (not shown). We also expressed RIP2-KD in Nod1-deficient MCF-7 C20 cells. As expected, treatment with $\gamma$ TriDAP did not induce apoptosis (Figure 2f). This result excludes alternative pathways involving RIP2 that lead to cell death but are independent of Nod1 expression.

To further substantiate the role of RIP2 in Nod1 signaling we used RIP2-targeting small-interfering RNAs (siRNAs). We identified a selective siRNA for RIP2 that reduced expression of RIP2 protein (Figure 2i). Expression of this siRNA resulted in diminished apoptosis and IL-8 secretion in $\gamma$ TriDAPstimulated cells (Figure $2 \mathrm{~g}$ and $\mathrm{h}$ ). Responses to TNF $\alpha$ were unchanged in cells that have reduced RIP2 expression. Taken together, these results show that RIP2 is essential for Nod1 signaling and further suggest that RIP2 may be a limiting component in the Nod1 signaling pathway. Further, we show that RIP2 CARD domain is essential but its kinase activity does not appear to be required to couple Nod1 activation with downstream signaling.

Expression of kinase-dead RIP2 sensitizes multiple cell lines to the effects of Nod1 activation. To determine if other human cell lines that respond to Nod1 activation by producing IL-8 show a similar involvement of RIP2 we examined a series of epithelial cell lines where we stably expressed empty vector (Blasto), RIP2-KD or RIP2- $\triangle$ CARD. These cell lines were treated with $\gamma$ TriDAP, MDP or TNF $\alpha$. HeLa, SK-BR3 and human intestinal epithelial (HT-29) cells stably expressing RIP2-KD but not RIP2- $\triangle$ CARD revealed an increased sensitivity to $\gamma$ TriDAP when compared with the parental cell lines expressing endogenous levels of RIP2 
(Figure 3a). In PCR studies not shown we determined that all cell lines tested expressed Nod1 mRNA whereas in contrast HT-29, SKBR3 and T47D but not HeLa cells expressed Nod2 mRNA. Interestingly, the Nod2-positive cell lines all produced increased IL-8 when RIP2-KD was stably expressed following addition of MDP. In contrast, the Nod2-negative HeLa cells failed to respond to MDP even in the presence of RIP2-KD showing the absolute requirement for Nod2. Expression of either RIP2-KD or RIP2- $\triangle$ CARD failed to change the pattern of TNF $\alpha$-induced IL-8 production in the same cell panel indicating the specificity of RIP2 for Nod1 and Nod2 signaling. It is interesting to note that these experiments were carried out in the absence of $\mathrm{CHX}$, suggesting that RIP2-KD dramatically changes the sensitivity of cells to $\gamma$ TriDAP. Similar protein expression levels of RIP2-KD and RIP2- $\triangle$ CARD was noted in all four lines as determined by Western blotting (Figure 3b). T47D cells stably expressing Nod1 or RIP2KD did not respond to $\gamma$ TriDAP despite strong expression of each protein. This reflects the variability of Nod1 responses from cell to cell. It is possible that $\gamma$ TriDAP did not enter inside the cells owing to some features of the plasma membrane of these cells. These cells might also express high levels of inhibitors on Nod1 itself or Nod1 signaling pathway. Taken together these data suggest that the observations made with MCF-7 cells are extendable to other cell lines of epithelial origin and that RIP2
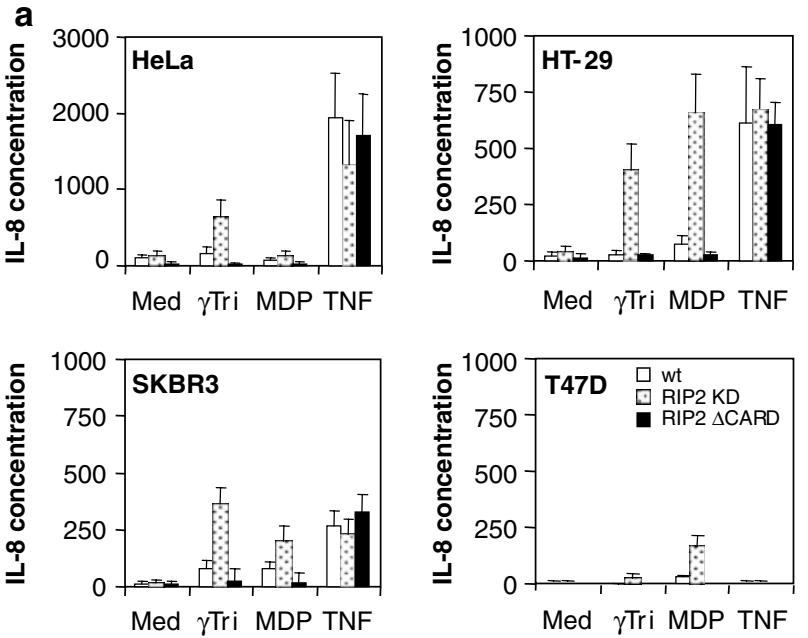

b

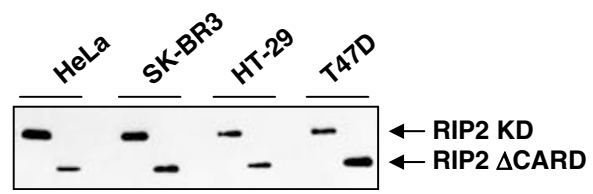

Figure 3 Expression of RIP2-KD sensitizes epithelial cells to $\gamma$ TriDAP and MDP. (a) HeLa, HT-29, SK-BR3 and T47D cells were stably transfected with MycRIP2-KD or Myc-RIP2- $\triangle$ CARD. Parental and stably transfected cells were left untreated or treated with $\gamma$ TriDAP, MDP $(20 \mu \mathrm{g} / \mathrm{ml}$ each) or TNF $\alpha(10 \mathrm{ng} / \mathrm{ml})$ for $24 \mathrm{~h}$. Cell supernatants were harvested and assayed for IL-8 secretion. Data are expressed as mean \pm S.D. of three independent experiments. (b) Expression of RIP2-KD and RIP2- $\triangle$ CARD proteins in the different cell lines was confirmed by immunoprecipitation of cell extracts with polyclonal anti-Myc antibody and immunoblotting using monoclonal anti-Myc 9E10 antibody provides a key control point in signaling via Nod1- and Nod2dependent cellular activation.

Results noted above provided us with an unexpected result whereby expression of RIP2-KD enhanced cellular responses to MDP in cell lines where Nod2 is expressed. Without RIP2KD expression these lines failed to respond to MDP despite the presence of Nod2 protein. This prompted to further explore the role of RIP2 in the Nod2 pathway using MCF-7 cells. We examined the effects of MDP on IL-8 production and apoptosis in cells stably expressing either Nod2 or RIP2-KD. We previously reported that MCF-7 cells overexpressing Nod2 do not undergo apoptosis upon MDP treatment although MDP treatment does induce release of $\mathrm{IL}-8$ protein. ${ }^{9}$ Unexpectedly, extensive cell death was observed in MCF-7 RIP2-KD cells treated with as little as $0.1 \mu \mathrm{g} / \mathrm{ml}$ of MDP. In contrast overexpression of Nod2 was not sufficient to support MDP-induced apoptosis (Figure 4a). We also noted that expression of RIP2 wt also supported MDP-induced apoptosis

a
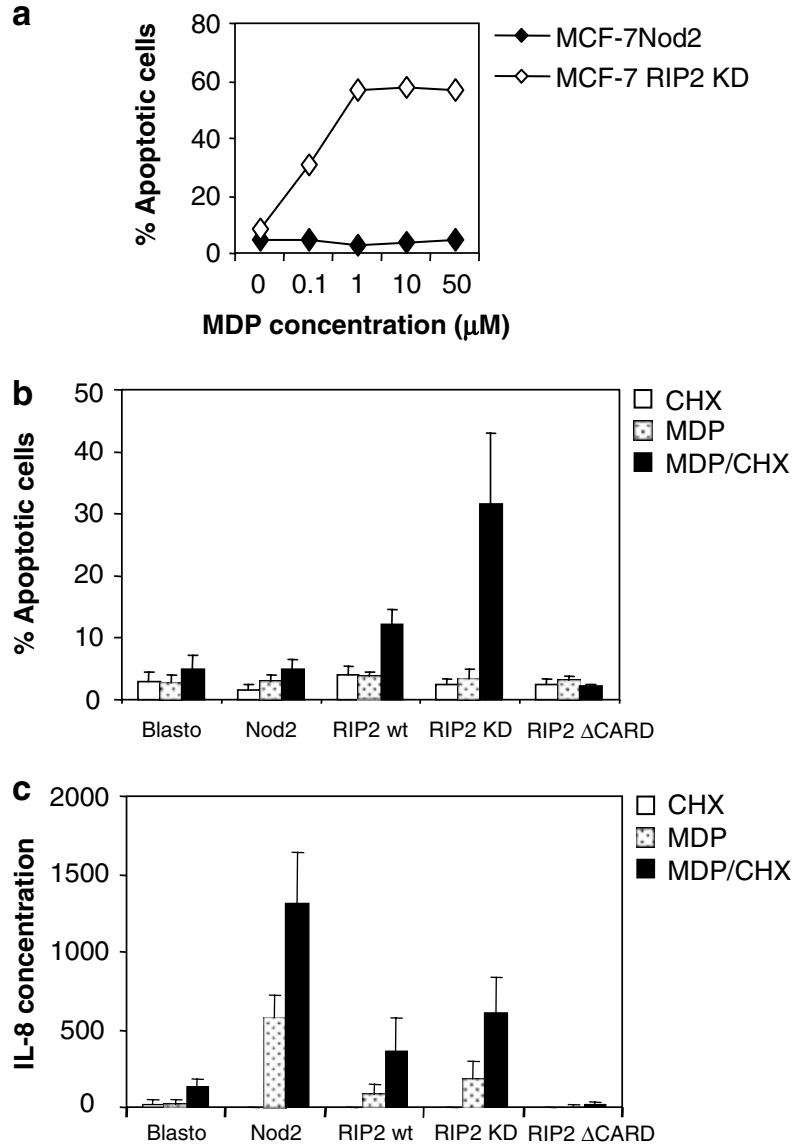

Figure 4 RIP2 sensitizes MCF-7 to MDP-induced apoptosis. (a) MCF-7 cells stably expressing Nod2 and or RIP2-KD were treated with increasing concentrations of MDP in the presence of $\mathrm{CHX}(3 \mu \mathrm{g} / \mathrm{ml})$ for $48 \mathrm{~h}$. Cells were incubated with PI and cell death was measured by flow cytometry. (b) MCF-7 cells stably transfected with Myc-Nod2, Myc-RIP2 wt, Myc-RIP2-KD and Myc-RIP2- $\triangle$ CARD were left untreated or treated with MDP $(20 \mu \mathrm{g} / \mathrm{ml})$ in the presence or absence of $\mathrm{CHX}(3 \mu \mathrm{g} /$ $\mathrm{ml})$ for $48 \mathrm{~h}$. Cells were incubated with PI and apoptotic cell death was measured by flow cytometry. (c) Cells were stimulated with MDP in the presence or absence of $\mathrm{CHX}(0.5 \mu \mathrm{g} / \mathrm{ml})$ for $24 \mathrm{~h}$. Cell supernatants were harvested and assayed for IL-8 secretion. Data are expressed as mean \pm S.D. of five independent experiments 
(Figure 4b). In contrast, MCF-7 cells expressing Nod2, RIP2 wt or RIP2-KD, but not RIP2- $\triangle$ CARD, all showed increased release of IL8 when compared with the parental MCF-7 cell line (Figure 4c). In their totality these data further support our contention that RIP2 provides a key regulatory function in both the Nod1 and Nod2 pathways coupling their activation to multiple downstream effects.

Nod1-dependent cytokine release requires TAK1. TAK1 has been implicated in Nod2 signaling. ${ }^{14}$ To examine whether TAK1 plays a role in Nod1 signaling in MCF-7 cells, we first evaluated the effects of a kinase-dead form of TAK1 (TAK1-KD) on Nod1-dependent JNK activation, induction of apoptosis and IL8 release. MCF-7 cells stably expressing TAK1 wt or TAK1-KD were treated with $\gamma$ TriDAP. We found that TAK1-KD but not TAK1 wt specifically inhibited JNK activation and IL-8 release (Figure $5 a$ and d). In contrast expression of TAK1-KD enhanced the sensitivity to Nod1-dependent cell death at least twofold when compared to the control MCF-7 line (Figure 5c). Expression of TAK1 wt, TAK1-KD and Nod1 was confirmed by Western blotting (Figure $5 \mathrm{~b}$ ). As the dominant-negative form of TAK1 can block Nod1 signaling, we next asked whether $\gamma$ TriDAP treatment resulted in TAK1 activation. Figure $5 \mathrm{e}$ shows that addition of $\gamma$ TriDAP caused phosphorylation of TAK1 that was maximal at $2 \mathrm{~h}$ showing similar kinetics as noted with JNK phosphorylation. In contrast TNF $\alpha$-induced phosphorylation of TAK 1 was detectable as early as $15 \mathrm{~min}$ after TNF $\alpha$ exposure. We further evaluated the role of TAK1 by using TAK1-targeting siRNAs. We identified two sets of specific siRNAs that specifically reduced the expression of TAK1 (Figure 5h). Depletion of TAK1 resulted in a dramatic decrease of IL-8 release (Figure 5f) and JNK activation (Supplementary Figure S1) in response to Nod1 activation and enhanced cell death (Figure $5 \mathrm{~g}$ ), further confirming the observations made with TAK1-KD.
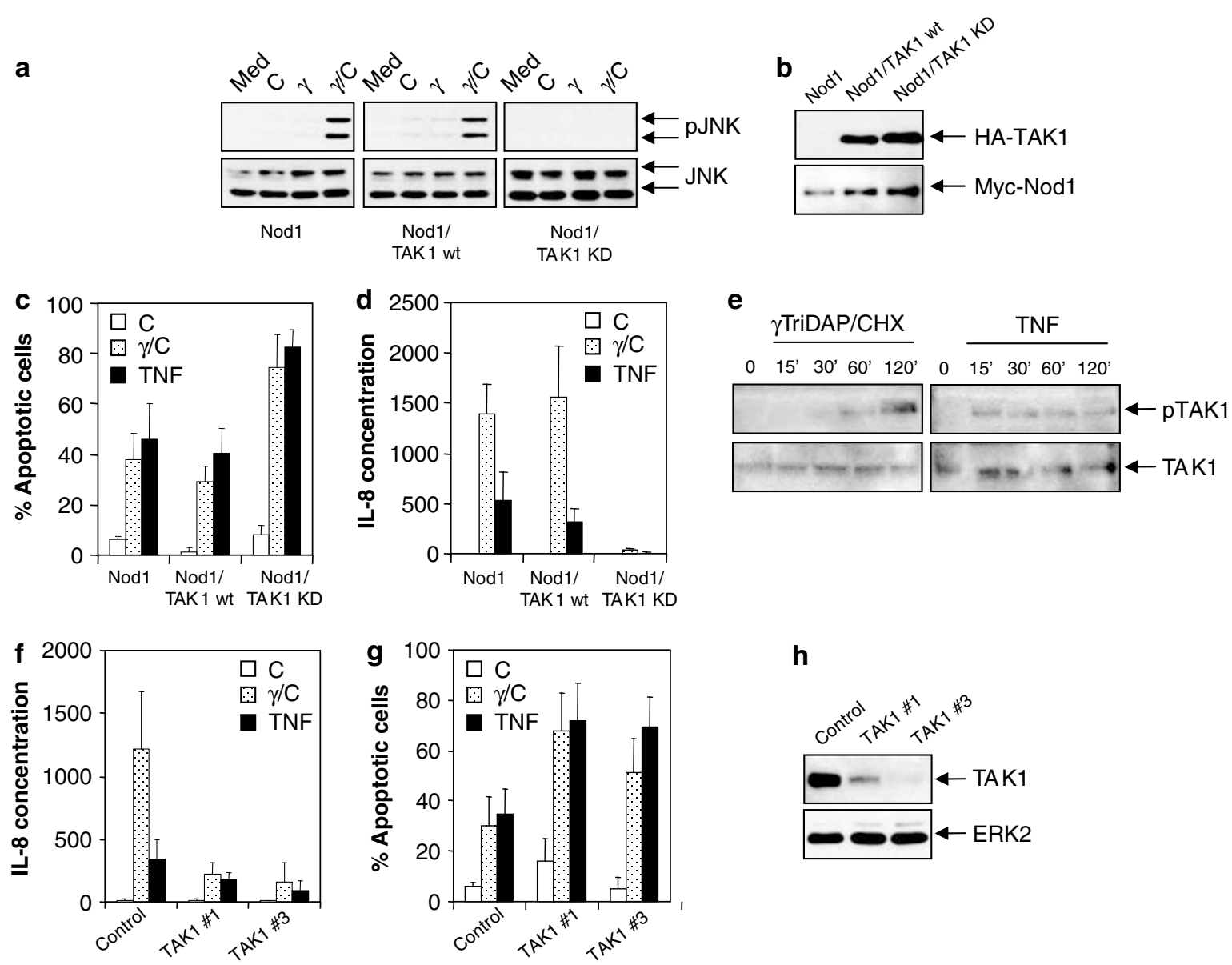

h

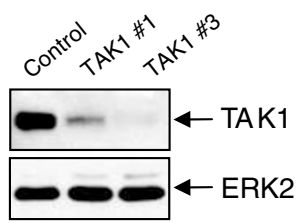

Figure 5 TAK1 controls JNK activation and cytokine release. (a) MCF-7 Blasto, MCF-7 TAK1-KD, MCF-7 Nod1 and MCF-7 TAK1-KD/Nod1were left untreated or treated with $\gamma \operatorname{TriDAP}(\gamma)$ in the presence or absence of $\mathrm{CHX}(\mathbf{c}, 0.5 \mu \mathrm{g} / \mathrm{ml})$ for $2 \mathrm{~h}$. Cell lysates were prepared and phosphorylation of JNK was analyzed using anti-phospho JNK antibody. (b) Expression of TAK1 wt, TAK1-KD and Nod1 proteins was confirmed by Western blotting using polyclonal anti-HA antibody and anti-Myc antibody, respectively. (c) Cells were treated with $\gamma$ TriDAP in the presence or absence of $\mathrm{CHX}(3 \mu \mathrm{g} / \mathrm{ml})$ for $48 \mathrm{~h}$ or TNF $\alpha$ for $18 \mathrm{~h}$. Cells were incubated with Pl and apoptotic cell death was measured by flow cytometry. (d) Cell supernatants were harvested and assayed for IL-8 secretion. Data are expressed as mean \pm S.D. of three independent experiments. (e) MCF-7 Nod1, were treated with $\gamma$ TriDAP in the presence of $\mathrm{CHX}(0.5 \mu \mathrm{g} / \mathrm{ml})$ for $2 \mathrm{~h}$. Cell lysates were prepared and phosphorylation of TAK1 was analyzed using anti-phospho TAK1 (Thr184/187) antibody. The same blots were reprobed for anti-TAK1, indicating equal protein loading. (f and $\mathbf{g}$ ) MCF-7 cells were transfected with TAK1-targeting siRNAs $(5 \mathrm{nM})$ and cultured for $72 \mathrm{~h}$. Cells were stimulated with $\mathrm{CHX}, \gamma$ TriDAP/CHX or TNF and apoptosis and IL-8 release determined. (f) Depletion of endogenous TAK1 protein was confirmed by Western blot using anti-TAK1 antibody. The same blots were reprobed for anti-ERK2, indicating equal protein loading 
Role of other protein adaptors and protein kinases in Nod1-dependent cell activation. We also examined the effect of expression of a variety of other molecules associated with signal transduction because of activities as either adaptor proteins or kinases. The effects of individual proteins on Nod1-dependent IL-8 production and on apoptosis are summarized for each protein in Table 1 (see also Supplementary Figure S2). These included CARD6, CARD8, PYNOD, ASC and ASC2. Deletion mutants of ASC were also used: the pyrin domain, reported to act as a dominant negative, ${ }^{15}$ as well as the CARD domain. Other signaling molecules involved in NF- $\kappa \mathrm{B}$ signaling pathway and apoptosis were also studied by overexpression of their respective dominant-negative forms (ASK1-KD, NIK-KD, FADD- $\Delta$ and TRAF6- $\Delta$ ). These proteins were stably overexpressed in MCF-7 Nod1 cells and apoptosis and IL-8 release assessed upon $\gamma$ TriDAP exposure. None of the tested proteins altered the Nod1 apoptotic signaling pathway in a significant manner. Expectedly, dominant-negative forms of NIK and $\mid \kappa \mathrm{B}-\alpha$ both blocked $\gamma$ TriDAP- and TNF $\alpha$-induced IL-8 secretion. Blocking of ASK1, a protein kinase involved in various apoptotic pathways, ${ }^{16}$ had no effect on Nod1 signaling pathway. Dominant-negative form of FADD did not alter Nod1 signaling, but significantly reduced TNF $\alpha$ induced apoptosis. We also observed that overexpression of ASC enhanced IL-8 release by twofold. This effect was also observed when only the CARD domain of ASC was introduced into cells. Additonal studies are underway to explore the role of ASC in Nod1 signaling.

Nod1-induced apoptosis is caspase $\mathbf{8}$ dependent. Inohara et al. ${ }^{11}$ reported that Nod1-enhanced caspase 9-dependent apoptosis. However these data were obtained after transient overexpression of Nod1 and various caspases. To identify the initiator caspase for Nod1-mediated cell apoptosis in MCF-7 cells we used approaches that included the expression of intracellular caspase inhibitors, the use of pharmacologic caspase inhibitors as well as depletion of caspases with siRNA. In results not shown we observed that

Table 1 Function of various signaling molecules in Nod1 signaling pathway

\begin{tabular}{lccccc}
\hline \multirow{2}{*}{ Signaling molecule } & \multicolumn{2}{c}{ Apoptosis } & & \multicolumn{2}{c}{ IL-8 production } \\
\cline { 2 - 3 } \cline { 5 - 6 } & $\gamma / \mathbf{C}$ & $\mathbf{T}$ & & $\gamma / \mathbf{C}$ & T \\
\hline Nod1 & ++ & +++ & & ++ & ++ \\
ASK1-KD & ++ & +++ & & ++ & +++ \\
NIK-KD & ++ & +++ & & + & - \\
I $\mathrm{n}$ B- $\alpha-\Delta$ & ++ & +++ & & - & - \\
FADD- $\Delta$ & ++ & + & & + & ++ \\
CARD6 & ++ & +++ & & ++ & ++ \\
CARD8 & ++ & +++ & & ++ & ++ \\
PYNOD & ++ & +++ & & ++ & ++ \\
TRAF6- $\Delta$ & ++ & +++ & & ++ & ++ \\
ASC & ++ & +++ & & +++ & ++ \\
ASC-CARD & ++ & +++ & & +++ & ++ \\
ASC-Pyrin & ++ & +++ & & ++ & ++ \\
ASC2 & ++ & +++ & & ++ & ++ \\
& & & & & ++ \\
\hline
\end{tabular}

MCF-7 Nod1 cells were stably cotransfected with indicated proteins. Cells were stimulated with $\gamma$ TriDAP/CHX and apoptosis and IL-8 release determined. For apoptosis assays: $(+) 2-20 \%$ cell death, $(++) 20-40 \%$ and $(+++)>40 \%$. For IL8 secretion: $(+)<500 \mathrm{ng} / \mathrm{ml},(++) 500-1500 \mathrm{ng} / \mathrm{ml}$ and $(+++)>1500 \mathrm{ng} / \mathrm{ml}$ the pharmacologic inhibitors of both caspase 8 and caspase 9 reduced Nod1-dependent apoptosis in MCF-7 cells. These data suggested a role for either caspase 8 or 9 as the initiator caspase. It is well known that the pharmacologic inhibitors are not completely specific so we utilized more precise approaches to distinguish between caspase 8 and caspase 9. We used several protein inhibitors that can be stably expressed in MCF-7 cells. CLARP (also known as c-FLIP) has been described as a specific inhibitor of caspase $8 .^{17}$ CLARP interacts with caspase 8 and FADD and blocks apoptosis induced by various ligand-receptor pairs including Fas, TNF $\alpha$ and TRAIL. ${ }^{18,19}$ When MCF-7 CLARP cells were incubated with $\gamma$ TriDAP cell death was totally inhibited, suggesting that the Nod1-induced apoptotic pathway overlaps with a pathway initiated by caspase 8 (Figure 6a). Another antiapoptotic protein, Bcl-2, prevents release of cytochrome $c$ from mitochondria and blocks the Apaf1/ caspase 9 complex. $^{20}$ Stable overexpression of $\mathrm{Bcl}-2$ in MCF-7 cells reduced $\gamma$ TriDAP-induced cell death to a limited extent suggesting the involvement of caspase 9 in Nod1 apoptotic pathway (Figure 6b). By contrast, neither CLARP or Bcl-2 expression reduced IL-8 release (Figure $6 \mathrm{c}$ and d) indicating their action on apoptotic pathways and not other Nod1-dependent events.

To further support our contention that caspase 8 is the initiator caspase, siRNA experiments were performed. MCF-7 Nod1 cells were transfected with specific caspase 8 and caspase 9 siRNAs that effectively depleted expression of the respective proteins (Figure 6e). Cells were stimulated with $\gamma$ TriDAP and we observed that caspase 8 but not caspase 9 depletion resulted in complete abrogation of $\gamma$ TriDAP-induced cell death (Figure 6f). In contrast neither siRNA reduced IL-8 release (Figure $6 \mathrm{~g}$ ). In totality, these experiments support the contention that caspase 8 plays a predominant role in initiating $\gamma$ TriDAP-induced apoptosis in MCF-7 cells.

\section{Discussion}

Nod1 is thought to be involved in innate immune responses through its function as a sensor of intracellular bacteria although the mechanisms involved in this process are not well defined. Before our recent work with MCF-7 cells most studies have been performed under conditions where Nod1 is overexpressed by transient transfection and consequently activation was constitutive and not ligand-dependent changes. $^{8,10,11,21}$ This has left a substantial gap in our knowledge about the regulation of Nod1 signaling when activation is initiated by a specific ligand. Thus, we wished to bridge this gap by studying Nod1 signaling in a cell line where we have also defined a unique Nod1-dependent biological activity demonstrable in an animal model. ${ }^{9}$ We have used the human breast cancer cell line MCF-7 to identify additional cellular components that regulate ligand-dependent Nod1 activation. Specifically we examined the pathways leading to Nod1-dependent JNK activation, IL-8 production and apoptosis.

Now, we have established a number of important features of Nod1 and its downstream signaling pathways in controlling multiple aspects of Nod1 signaling leading to JNK activation, 

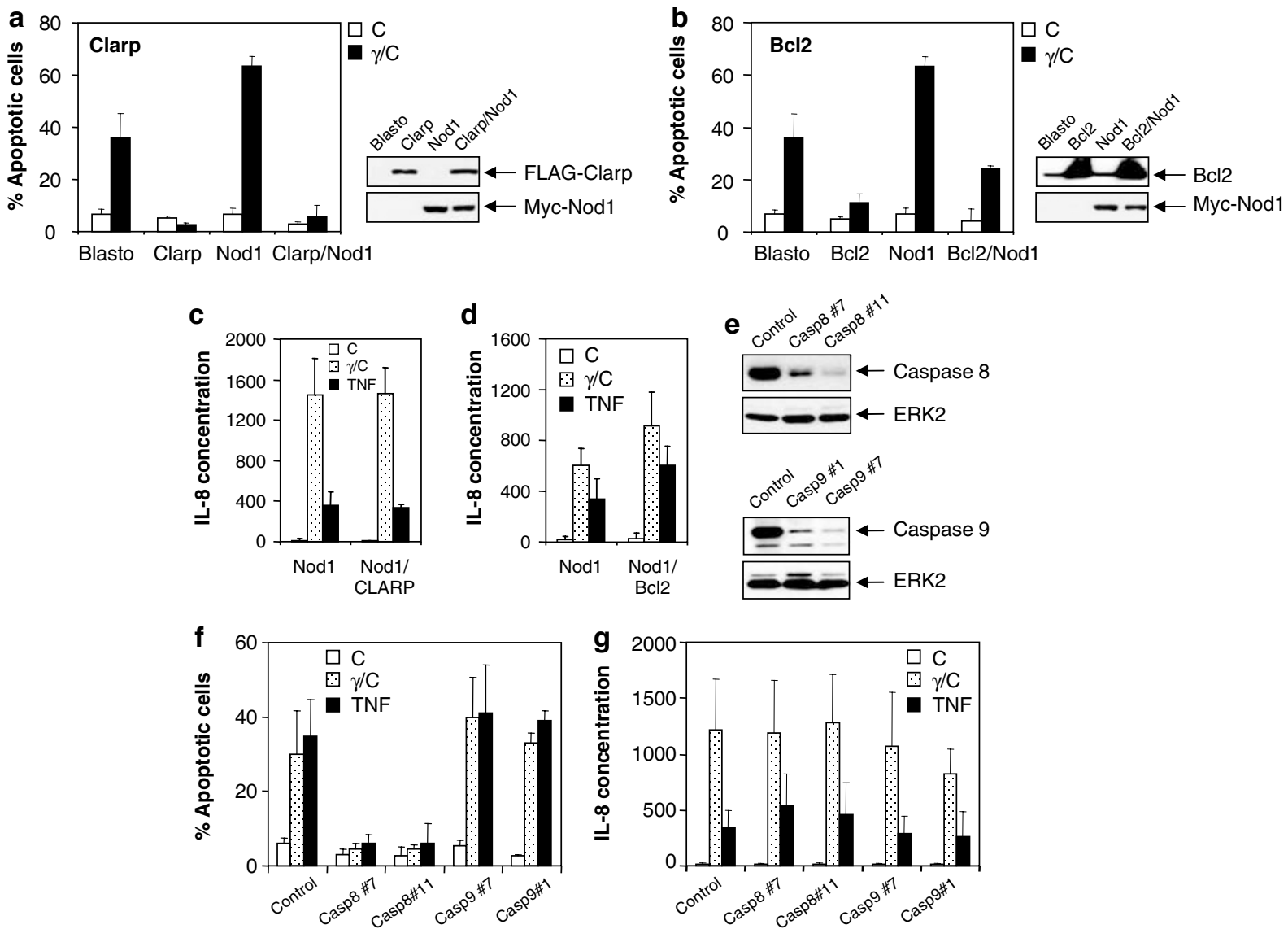

Figure 6 Nod1-dependent apoptosis requires caspase 8. (a and $\mathbf{b})$ CLARP completely prevents $\gamma$ TriDAP-induced apoptosis whereas Bcl2 inhibits only partially. MCF-7 CLARP, MCF-7 CLARP/Nod1, MCF-7 Bcl2 and MCF-7 Bcl2/Nod1were left untreated or treated with $\gamma \operatorname{TriDAP}(\gamma)$ in the presence or absence of CHX (c, $3 \mu \mathrm{g} / \mathrm{ml})$ for $48 \mathrm{~h}$. Cells were incubated with $\mathrm{PI}$ and apoptotic cell death was measured by flow cytometry. Expression of cFLIP/CLARP, Bcl2 and Nod1proteins was confirmed by Western blotting using anti-FLAG, anti-Bcl2 and anti-Myc antibodies, respectively. (c and d) Cell supernatants were harvested and assayed for IL-8 secretion. (e) Depletion of endogenous caspase 8 and caspase 9 proteins using specific siRNAs was analyzed by Western blot using anti-caspase 8 and caspase 9 antibodies. The same blots were reprobed for antiERK2, indicating equal protein loading. ( $f$ and $\mathbf{g})$ MCF-7 cells were transfected with caspase 8 and caspase 9 -targeting siRNAs ( $5 \mathrm{nM}$ ) and cultured for $72 \mathrm{~h}$. Cells were stimulated with $\mathrm{CHX}, \gamma \mathrm{TriDAP} / \mathrm{CHX}$ or TNF $\alpha$ and apoptosis and IL-8 release determined

cytokine production and induction of apoptosis. We showed that the kinase activity of RIP2 is not required for its function in Nod1 signaling pathways. In fact, the extent of changes linked to Nod1 was enhanced when compared to either the parental cells or those overexpressing RIP2-KD. We also confirmed the importance of the CARD domain of RIP2 in the Nod1 pathway as expression of RIP2- $\triangle$ CARD prevented all Nod1dependent signaling. Another kinase, TAK1, is activated following addition of the Nod1 ligand. Several lines of evidence support a key role for TAK1 in JNK activation and IL-8 production but not apoptosis. These data include the expression of a dominant-negative form of TAK1 as well as siRNA depletion of endogenous TAK1. Finally we provided multiple lines of evidence to establish a key role for caspase 8 as the initiator caspase in Nod1-dependent apoptosis in MCF-7 cells.

The $\mathrm{P}$-loop is found in a number of proteins known to regulate apoptosis including Nod1 ${ }^{22-24}$ Here we confirmed that the P-loop residue K208 plays a key role in the consequences of Nod1 activation including JNK phosphorylation, IL-8 production and apoptosis. This finding suggests that the P-loop is involved in key step that is central to the most proximal events associated with ligand-dependent activation. This is likely to reflect the oligomerization of Nod1 and the subsequent formation of a multiprotein complex essential for downstream activation pathways.

It is well known that $\mathrm{CHX}$ used at high concentrations promotes apoptosis through inhibition of transcription of antiapoptotic molecules such as c-FLIP or other inducible molecules. ${ }^{25}$ Used at lower concentration, $\mathrm{CHX}$ enhances signaling pathways activated by extracellular stimuli by inducing a low level of cell stress although the exact mechanisms whereby this occurs are unknown. ${ }^{26-28}$ Several mechanisms have been proposed to explain gene superinduction by $\mathrm{CHX}$. These include an increase in mRNA stability, ${ }^{29}$ increase in transcription, ${ }^{30,31}$ and stimulation of intracellular signaling pathways. ${ }^{27,32}$ Moreover, we observed that $\gamma$ TriDAP could induce apoptosis in the absence of $\mathrm{CHX}$ in MCF-7 and SK-BR3 cells (Supplementary Figure S3a-b). Cells primed with IFN $\gamma$ underwent extensive cell death when exposed to $\gamma$ TriDAP. Finally, we observed that $\gamma$ TriDAP enhanced TNF $\alpha$-induced apoptosis in MCF-7 cells without 
added CHX (Supplementary Figure S3c-d). In totality, the data provided here together with Supplementary Data argue strongly for the physiological relevance of the Nod1-induced cell pathway.

The CARD domain of RIP2 has been shown to be important for a number of signaling pathways in both the innate and adaptive immune systems. ${ }^{33-35}$ For example, RIP2-deficient cells show impaired MAPK and cytokine responses that depend on TLR or IL-1/IL-18 receptor signaling. Here, we have shown that RIP2 requires its CARD domain but not its kinase activity in order to participate in Nod1-dependent signaling. Interestingly, kinase-dead RIP2 has also been shown to support Nod2 signaling. RIP2 has been reported to depend on TRAF $6,{ }^{34,36}$ but here we noted that expression of a dominant-negative form of TRAF6 did not impair $\gamma$ TriDAPinduced cell activation. Some cell lines expressing either endogenous or expressed Nod2, including MCF-7 cells, that failed to respond to the Nod2 ligand MDP, become responsive to MDP when RIP2-KD is expressed. Thus in their totality our data supports the contention that RIP2 is an obligatory component in all Nod1-dependent events and appears to be a key control point in both Nod1 and Nod2 activation pathways. However, the role of its intrinsic kinase activity in these signaling pathways remains unknown.

Here we also showed that TAK1 appears to play an essential role in Nod1 signaling in MCF-7 cells. TAK1 has been shown to be important in TNF $\alpha, \mathrm{IL}-1 \beta$ and LPS signaling cascades. $^{37-39}$ Recently, a crosstalk between Nod2 and TAK1 has been reported indicating that TAK1 is required for Nod2-dependent NF- $\kappa \mathrm{B}$ activation and that Nod2 may act reciprocally to block TAK1-induced NF- $\kappa \mathrm{B}$ activation in some cell types. ${ }^{14}$ Nod1-induced phosphorylation of TAK1 peaked at $2 \mathrm{~h}$ after addition of $\gamma$ TriDAP in MCF-7 cells. This delayed activation may reflect the kinetic of entry of the peptide in cells rather than an indirect effect of $\gamma$ TriDAP. We observed that JNK activation was not changed in MCF-7 cells stably expressing a dominant-negative form of $\left.\right|_{\kappa} \mathrm{B}-\alpha\left(\mathrm{l}_{\kappa} \mathrm{B}-\alpha-\Delta\right)$, ruling out a possible role of $\mathrm{NF}-\kappa \mathrm{B}$ by a feedback mechanism (Supplementary Figure S4). Importantly, I $\kappa \mathrm{B}-\alpha-\Delta$ blocked both TNF- and $\gamma$ TriDAP-induced IL- 8 production showing that this construct acts as a true dominant-negative form. We further showed an important role for TAK1 in Nod1-induced JNK activation and in IL-8 production. Interestingly, expression of TAK1-KD-enhanced Nod1-dependent apoptosis. Finally, we confirmed these findings using siRNA depletion further supporting our conclusions that TAK1 functions at a bifurcation in the Nod1 signaling pathways.

We have also provided multiple lines of evidence supporting the contention that Nod1 initiates a caspase 8-dependent cell death pathway. Specific inhibitors of apoptosis such as CLARP, a specific caspase 8 inhibitor, totally abrogated Nod1-induced cell killing suggesting that the extrinsic apoptotic pathway or receptor-dependent pathway plays the most important role. In contrast, overexpression of antiapoptotic $\mathrm{Bcl}-2$ molecule prevented Nod1-induced apoptosis in a limited manner. Activation of caspase 9 is likely a secondary event during the apoptotic process triggered by $\gamma$ TriDAP. Apoptosis can occur through different pathways. It has been reported that type I cells produce large amounts of active caspase 8 that can directly trigger an apoptotic response bypassing the

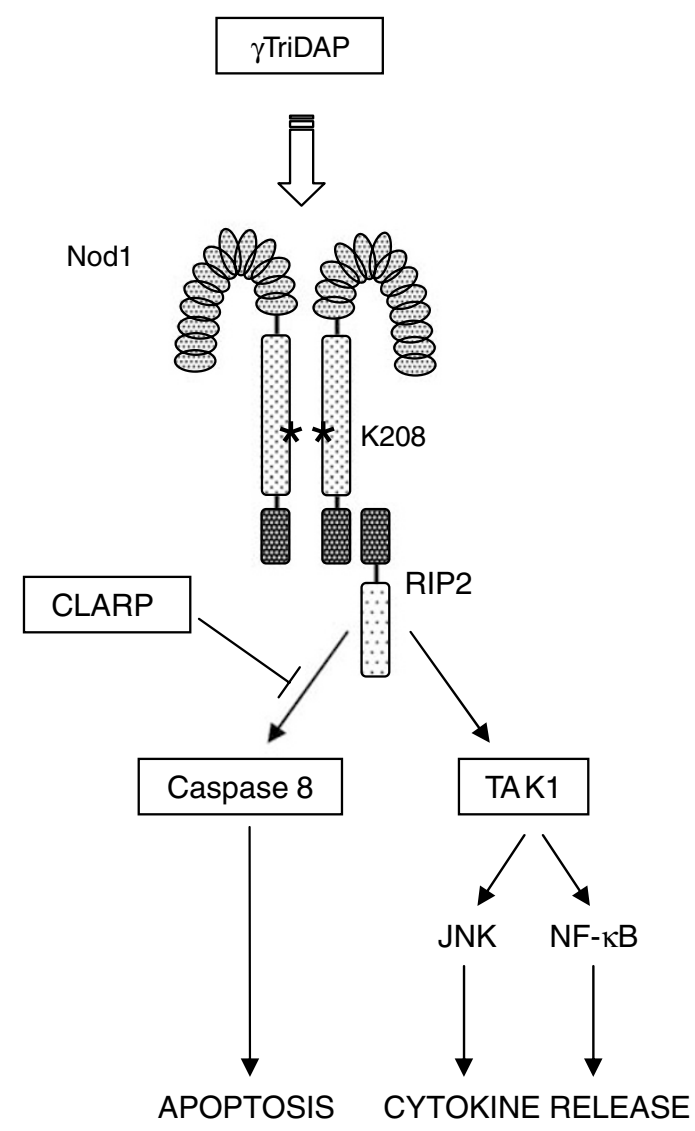

Figure 7 Summary of Nod1-mediated signaling pathways. All Nod1 signaling pathways are controlled by RIP2. Activation of JNK and NF- $\kappa B$ is mediated by TAK1, whereas the apoptotic pathway is controlled by caspase 8 . ${ }^{*}$ Indicates the position of K208 in the NBD domain of Nod1

mitochondrial pathway. ${ }^{40}$ Apoptosis cannot be blocked by overexpression of $\mathrm{Bcl} 2$ in these cells as caspase activation is independent of the mitochondria. By contrast, in type II cells such as MCF-7 cells caspase 8-initiated death requires the involvement of the mitochondrial pathway, thus allowing $\mathrm{Bcl} 2$ to partially suppress the apoptotic cascade. Our findings stand in contrast to a previous study that reported on effects of overexpression of Nod1 on proteolytic processing of procaspase 9 but not caspase $8 .^{11}$ However, our data reflect endogenous pathways triggered by a specific Nod1 ligand. Thus, we contend that the caspase 8 dependency reflects a physiologically relevant pathway.

The results described herein indicate that Nod1 signaling complex leads to activation of at least two distinct effector functions, JNK activation and cytokine release and induction of apoptosis. The model shown in Figure 7 indicates that signaling begins with oligomerization of Nod1 through its NBD domain in the presence $\gamma$ TriDAP. RIP2 is subsequently recruited to Nod1 through CARD-CARD interactions and triggers events that lead to cell death controlled by caspase 8, and JNK activation and cytokine release controlled by TAK1.

\section{Materials and Methods}

Cell culture. Human breast cancer cell lines (MCF-7, SKBR3 and T47D) and HT-29 cells were maintained in Dulbecco's modified Eagle's medium supplemented 
with $10 \%$ fetal bovine serum, $2 \mathrm{mM}$ glutamine, $100 \mathrm{U} / \mathrm{ml}$ penicillin and $10 \mu \mathrm{g} / \mathrm{ml}$ streptomycin.

Reagents. Anti-phospho JNK (Thr183/Tyr185), anti-JNK, anti-phospho TAK1 (Thr184/187), anti-TAK1, anti-caspase 8 and anti-caspase 9 antibodies were from Cell Signaling Technology Inc (Beverly, MA, USA). M2 anti-FLAG monoclonal antibody was from Sigma Chemicals Co. (St Louis, MO, USA). Polyclonal rabbit anti-Myc antibody was from Upstate Biotechnology (Lake Placid, NY, USA) and monoclonal anti-Myc $9 \mathrm{E} 10$ and anti-ERK2 were from Santa Cruz Biotechnology Inc (Santa Cruz, CA, USA). Monoclonal anti-HA 12CA5 antibody was from Roche Applied Science (Indianapolis, IN, USA). Polyclonal rabbit anti-RIP2 was from Cayman Chemical (Ann Arbor, MI, USA). Protein A-Sepharose was from Amersham Pharmacia Biotech Ltd (Piscataway, NJ, USA). CHX was obtained from Sigma. Human recombinant TNF $\alpha$ was purchased from R\&D Systems (Minneapolis, MN, USA). MDP was purchased from BACHEM (Torrance, CA, USA). $\gamma$ TriDAP and $\alpha$ TriDAP were chemically synthesized by Anaspec Inc (San Jose, CA, USA).

\section{Mammalian expression constructs and site-directed mutagenesis. Human FLAG-Nod1, FLAG-Nod2 and cDNAs were obtained from $\mathrm{Dr}$ G Nuňez (University of Michigan Medical School). Human Myc-RIP2 wt and Myc-RIP2 (K47A) were a gift from Dr C Vincenz (University of Michigan Medical School). Nod1 mutant K208R was constructed by site-directed mutagenesis with overlapping extension method by PCR using Nod1 wt DNA templates. Myc-RIP2 $\triangle \mathrm{CARD}$ was generated by deletion of the carboxy-terminal CARD domain and cloning into the pcDNA4/Myc/His plasmid (Invitrogen, Carlsbad, CA, USA). HA-TAK1 wt and HA-TAK1-KD (K63W) were described previously. ${ }^{39}$ Open-reading frames of the following genes (CARD6, CARD8, PYNOD, ASC, ASC2, I $1 \kappa \mathrm{B}-\alpha$ and FADD) were amplified by PCR and cloned into pcDNA3/Myc, pFLAG-CMV5.1 or pcDNA3/HA vectors. The nucleotide sequences were all confirmed by DNA sequencing.}

Retroviral transfections. The various genes described above were cloned into pMSCV-Blasto, pBabe-Puro or pBabe-Neo retroviral vectors. MCF-7 cells were stably transfected as described. Briefly, amphotropic 293 cells were transfected with pMSCV or pBabe vectors encoding for various proteins in 10-cm Petri dishes using Lipofectamine/Reagent Plus (Invitrogen). Twenty-four hour post-transfection, cells were incubated overnight at $32^{\circ} \mathrm{C}$ to produce viral particles. Target cells were infected the next day with 293 cells supernatants containing recombinant retroviral particles and in the presence of $10 \mu \mathrm{g} / \mathrm{ml}$ polybrene (Sigma) by centrifugation at $2500 \times \mathrm{g}$ for $90 \mathrm{~min}$ at $32^{\circ} \mathrm{C}$. Cells were selected with $10 \mu \mathrm{g} / \mathrm{ml}$ blasticidin $\mathrm{S}$ (Calbiochem), $5 \mu \mathrm{g} / \mathrm{ml}$ puromycin (Calbiochem) or $500 \mu \mathrm{g} / \mathrm{ml}$ gentamycin (Invitrogen). The expression of all constructs was confirmed by Western blot analysis. MCF-7 C20 cells were infected with Myc-Nod1. Single colonies were obtained by limiting dilution. Clones were tested for expression of Nod1 and selected for further analysis.

Preparation of cell lysates. Cells were washed extensively and lysed in lysis buffer containing $50 \mathrm{mM}$ Hepes, $100 \mathrm{mM} \mathrm{NaCl}, 2 \mathrm{mM}$ EDTA, $10 \%$ glycerol, $1 \%$ Nonidet $\mathrm{P}-40,14 \mu \mathrm{M}$ pepstatin $\mathrm{A}, 100 \mu \mathrm{M}$ leupeptin, $3 \mathrm{mM}$ benzamidine, $1 \mathrm{mM}$ PMSF, $1 \mathrm{mM}$ sodium pyrophosphate, $10 \mathrm{mM}$ sodium orthovanadate, $100 \mathrm{U} / \mathrm{ml}$ aprotinin, $100 \mathrm{mM}$ sodium fluoride. After incubation for $30 \mathrm{~min}$ on ice, cell lysates were centrifuged ( 14000 r.p.m. for $10 \mathrm{~min}$ at $4^{\circ} \mathrm{C}$ ) and the supernatants were recovered.

Immunoprecipitation and Western blot analysis. Cell lysates were precleared three times for $20 \mathrm{~min}$ at $4^{\circ} \mathrm{C}$ with $20 \mu$ of protein A-Sepharose beads, and mixed with $5 \mu \mathrm{g}$ of M2 Mab for $3 \mathrm{~h}$ at $4^{\circ} \mathrm{C}$ under constant agitation. Immune complexes were allowed to bind to $20 \mu \mathrm{l}$ protein A-Sepharose beads overnight, beads were washed three times with lysis buffer and the washed beads resuspended in $30 \mu \mathrm{l}$ of Laemmli buffer and boiled for $7 \mathrm{~min}$. Immunoprecipitates were separated on SDS-PAGE and transferred to nitrocellulose membranes. Filters were blocked with $3 \%$ BSA in blocking buffer (TBS, 50 mM Tris.Cl, pH 7.5; $150 \mathrm{mM} \mathrm{NaCl} ; 0.1 \%$ Tween 20), and incubated with anti-FLAG, anti-HA or anti-Myc antibody for $2 \mathrm{~h}$ and with peroxidase-conjugated secondary antibody for $1 \mathrm{~h}$ at ambient temperature. Specific bands were revealed using the ECL Plus system (Amersham).
Cell viability assays. Cells were plated at a density of $8 \times 10^{4}$ cells/well in 24 well plates, and stimulated as indicated for 2 days. Cell supernatants were collected and pooled with adherent cells that were detached with trypsin-EDTA (Invitrogen). Subsequently, cells were harvested, washed twice in FACS buffer (PBS containing $1 \% \mathrm{FCS}$ and $0.1 \% \mathrm{NaN}_{3}$ ) and resuspended in propidium iodide-containing FACS buffer $(4 \mu \mathrm{g} / \mathrm{ml})$. The extent of cell death was analyzed with a FACSCalibur flow cytometer (Becton Dickinson, Mountain View, CA, USA)

IL-8 ELISA. Concentration of IL-8 in cell supernatants was measured by ELISA using 96-well Immunlon plates (Dynatech Laboratories, Chantilly, VA, USA). ELISA was performed using the mAb MAB208 for capture and a biotinylated polyclonal rabbit anti-human IL-8 Ab (R\&D Systems, Minneapolis, MN, USA) followed by streptavidin HRP for detection. ELISA was developed using o-phenylenediamine (Sigma) as a substrate, and OD was determined at a wavelength of $490 \mathrm{~nm}$ using a Spectramax plate reader (Molecular Devices, Sunnyvale, CA, USA). All values were interpolated from a semilog fit of a curve generated from IL-8 standards.

siRNA assays. The following siRNAs used in this study were purchased from QIAGEN: RIP2 (\#3), caspase 8 (\#7 and \#11), caspase 9 (\#1 and \#7) and TAK1 (\#1 and \#3). MCF-7 cells were transfected with $5 \mathrm{nM}$ double-stranded siRNA using HiPerfect transfection reagent (Qiagen) according to the manufacturer's protocol. At $72 \mathrm{~h}$ after transfection, cells were subjected to various assays.

Acknowledgements. This work was supported by National Institutes of Health Grants Al 15136, GM37696 and U54 Al54523 and Novartis Grant SFP 1568 (to RJU).

1. Ting JP, Davis BK. Caterpiller: a novel gene family important in immunity, cell death, and diseases. Annu Rev Immunol 2004; 23: 387-414.

2. Werts C, Girardin SE, Philpott DJ. TIR, CARD and PYRIN: three domains for an antimicrobial triad. Cell Death Differ 2006; 13: 798-815.

3. Ogura Y, Inohara N, Benito A, Chen FF, Yamaoka S, Nunez G. Nod2, a Nod1/Apaf-1 family member that is restricted to monocytes and activates NF-kappaB. J Biol Chem 2001 276: $4812-4818$.

4. Girardin SE, Boneca IG, Viala J, Chamaillard M, Labigne A, Thomas G et al. Nod2 is a general sensor of peptidoglycan through muramyl dipeptide (MDP) detection. J Biol Chem 2003; 278: 8869-8872.

5. Inohara N, Ogura Y, Fontalba A, Gutierrez O, Pons F, Crespo J et al. Host recognition of bacterial muramyl dipeptide mediated through NOD2. Implications for Crohn's disease. J Biol Chem 2003; 278: 5509-5512.

6. Girardin SE, Boneca IG, Carneiro LA, Antignac A, Jehanno M, Viala J et al. Nod1 detects a unique muropeptide from Gram-negative bacterial peptidoglycan. Science 2003; 300: $1584-1587$.

7. Inohara N, Koseki T, Lin J, del Peso L, Lucas PC, Chen FF et al. An induced proximity model for NF-kappa B activation in the Nod1/RICK and RIP signaling pathways. J Biol Chem 2000; 275: 27823-27831.

8. Girardin SE, Tournebize R, Mavris M, Page AL, Li X, Stark GR et al. CARD4/Nod1 mediates NF-kappaB and JNK activation by invasive Shigella flexneri. EMBO Rep 2001; 2 $736-742$.

9. da Silva Correia J, Miranda Y, Austin-Brown N, Hsu J, Mathison J, Xiang R et al. Nod1dependent control of tumor growth. Proc Natl Acad Sci USA 2006; 103: 1840-1845.

10. Bertin J, Nir WJ, Fischer CM, Tayber OV, Errada PR, Grant JR et al. Human CARD4 protein is a novel CED-4/Apaf-1 cell death family member that activates NF-kappaB. J Biol Chem 1999; 274: 12955-12958.

11. Inohara N, Koseki T, del Peso L, Hu Y, Yee C, Chen S et al. Nod1, an Apaf-1-like activator of caspase-9 and nuclear factor-kappaB. J Biol Chem 1999; 274: 14560-14567.

12. Kobayashi K, Inohara N, Hernandez LD, Galan JE, Nunez G, Janeway CA et al. RICK Rip2/CARDIAK mediates signalling for receptors of the innate and adaptive immune systems. Nature 2002; 416: 194-199.

13. Chin Al, Dempsey PW, Bruhn K, Miller JF, Xu Y, Cheng G. Involvement of receptor-interacting protein 2 in innate and adaptive immune responses. Nature 2002; 416: 190-194.

14. Chen CM, Gong Y, Zhang M, Chen JJ. Reciprocal cross-talk between Nod2 and TAK1 signaling pathways. J Biol Chem 2004; 279: 25876-25882.

15. Stehlik C, Fiorentino L, Dorfleutner A, Bruey JM, Ariza EM, Sagara J et al. The PAAD/ PYRIN-family protein ASC is a dual regulator of a conserved step in nuclear factor kappaB activation pathways. J Exp Med 2002; 196: 1605-1615.

16. Ichijo H, Nishida E, Irie K, ten Dijke P, Saitoh M, Moriguchi T et al. Induction of apoptosis by ASK1, a mammalian MAPKKK that activates SAPK/JNK and p38 signaling pathways. Science 1997; 275: 90-94.

17. Irmler M, Thome M, Hahne M, Schneider P, Hofmann K, Steiner V et al. Inhibition of death receptor signals by cellular FLIP. Nature 1997; 388: 190-195. 
18. Muzio M, Stockwell BR, Stennicke HR, Salvesen GS, Dixit VM. An induced proximity mode for caspase-8 activation. J Biol Chem 1998; 273: 2926-2930.

19. Boldin MP, Goncharov TM, Goltsev YV, Wallach D. Involvement of MACH, a nove MORT1/FADD-interacting protease, in Fas/APO-1- and TNF receptor-induced cell death Cell 1996; 85: 803-815.

20. Gross A, McDonnell JM, Korsmeyer SJ. BCL-2 family members and the mitochondria in apoptosis. Genes Dev 1999; 13: 1899-1911.

21. Hisamatsu T, Suzuki M, Podolsky DK. Interferon-gamma augments CARD4/NOD1 gene and protein expression through interferon regulatory factor-1 in intestinal epithelial cells. J Biol Chem 2003; 278: 32962-32968.

22. Hu Y, Ding L, Spencer DM, Nunez G. WD-40 repeat region regulates Apaf-1 selfassociation and procaspase-9 activation. J Biol Chem 1998; 273: 33489-33494.

23. Chinnaiyan AM, Chaudhary D, O'Rourke K, Koonin EV, Dixit VM. Role of CED-4 in the activation of CED-3. Nature 1997; 388: 728-729.

24. Chaudhary D, O'Rourke K, Chinnaiyan AM, Dixit VM. The death inhibitory molecules CED9 and CED-4L use a common mechanism to inhibit the CED-3 death protease. J Biol Chem 1998; 273: 17708-17712.

25. Santiago B, Galindo M, Palao G, Pablos JL. Intracellular regulation of Fas-induced apoptosis in human fibroblasts by extracellular factors and cycloheximide. J Immunol 2004; 172: $560-566$.

26. Madevan LC. Signalling and superinduction. Nature 1991; 349: 747-748.

27. Zinck R, Cahill MA, Kracht M, Sachsenmaier C, Hipskind RA, Nordheim A. Protein synthesis inhibitors reveal differential regulation of mitogen-activated protein kinase and stress-activated protein kinase pathways that converge on Elk-1. Mol Cell Biol 1995; 15 : 4930-4938.

28. Mattson MP, Furukawa K. Anti-apoptotic actions of cycloheximide: blockade of programmed cell death or induction of programmed cell life? Apoptosis 1997; 2: 257-264.

29. Ohh M, Takei F. Regulation of ICAM-1 mRNA stability by cycloheximide: role of serine/ threonine phosphorylation and protein synthesis. J Cell Biochem 1995; 59: 202-213.
30. Greenberg ME, Hermanowski $A L$, Ziff EB. Effect of protein synthesis inhibitors on growth factor activation of c-fos, c-myc, and actin gene transcription. Mol Cell Biol 1986; 6 : 1050-1057.

31. Roger T, Out TA, Jansen HM, Lutter R. Superinduction of interleukin-6 mRNA in lung epithelial H292 cells depends on transiently increased C/EBP activity and durable increased mRNA stability. Biochim Biophys Acta 1998; 1398: 275-284.

32. Mahadevan LC. Signalling and superinduction. Nature 1991; $349: 747-748$.

33. Thome M, Hofmann K, Burns K, Martinon F, Bodmer JL, Mattmann C et al. Identification of CARDIAK, a RIP-like kinase that associates with caspase-1. Curr Biol 1998; 8: 885-888.

34. McCarthy JV, Ni J, Dixit VM. RIP2 is a novel NF-kappaB-activating and cell death-inducing kinase. J Biol Chem 1998; 273: 16968-16975.

35. Inohara N, del Peso L, Koseki T, Chen S, Nunez G. RICK, a novel protein kinase containing a caspase recruitment domain, interacts with CLARP and regulates CD95-mediated apoptosis. J Biol Chem 1998; 273: 12296-12300.

36. Lu C, Wang A, Dorsch M, Tian J, Nagashima K, Coyle AJ et al. Participation of Rip2 in lipopolysaccharide signaling is independent of its kinase activity. J Biol Chem 2005; 280: 16278-16283.

37. Blonska M, Shambharkar PB, Kobayashi M, Zhang D, Sakurai H, Su B et al. TAK1 is recruited to the tumor necrosis factor-alpha (TNF-alpha) receptor 1 complex in a receptorinteracting protein (RIP)-dependent manner and cooperates with MEKK3 leading to NF-kappaB activation. J Biol Chem 2005; 280: 43056-43063.

38. Sato S, Sanjo H, Takeda K, Ninomiya-Tsuji J, Yamamoto M, Kawai T et al. Essential function for the kinase TAK1 in innate and adaptive immune responses. Nat Immunol 2005; 6: $1087-1095$

39. Lee J, Mira-Arbibe L, Ulevitch RJ. TAK1 regulates multiple protein kinase cascades activated by bacterial lipopolysaccharide. J Leukoc Biol 2000; 68: 909-915.

40. Scaffidi C, Fulda S, Srinivasan A, Friesen C, Li F, Tomaselli KJ et al. Two CD95 (APO-1/ Fas) signaling pathways. EMBO J 1998; 17: 1675-1687.

\section{Supplementary Information accompanies the paper on Cell Death and Differentiation website (http://www.nature.com/cdd)}

